\title{
AGE COMPARATIVE STUDY ON SPINAL ANAESTHESIA AND AUDITORY FUNCTIONS
}

Bansode Apeksha, Lalita Afzal, Valsamma Abraham, Navneet Kumar

1. Resident, Department of Anaesthesia, Christian Medical College. Ludhiana, Punjab.

2. Professor, Department of Anaesthesia, Christian Medical College. Ludhiana, Punjab.

3. Professor \& Head, Department of Anaesthesia, Christian Medical College. Ludhiana, Punjab.

4. Associate Professor, Department of ENT, Christian Medical College. Ludhiana, Punjab.

\section{CORRESPONDING AUTHOR}

Dr. Valsamma Abraham

Professor \& Head,

Department of Anaesthesia, Christina Medical College, Ludhiana.

E-mail: dr_valsa@yahoo.com

Ph: 00919915326547.

ABSTRACT: BACKGROUND: Decreased hearing after various procedures involving opening of the dura mater resulting in leakage of cerebro spinal fluid (CSF) has been reported previously. We conducted this study as very few studies have explored the hypothesis that patient age may affect hearing loss after subarachnoid block. OBJECTIVE: To compare difference in hearing loss after spinal anaesthesia between young and elderly patients. METHODS: Prospective study conducted on 90 patients of either gender, ASA 1 or 2 scheduled for elective surgery under spinal anaesthesia. The group allocation was as follows: group Y: 30 patients aged $\leq 30$ years; group M: 30 patients aged 31-60 years and group E: 30 patients $\geq 61$ years. All subjects underwent clinical oto-laryngological examination and pure tone audiometry ( PTA) in both ears under standardized conditions on the day prior to surgery (control value) and on the $2^{\text {nd }}$ post spinal day. Significant hearing loss was defined as difference of $>15 \mathrm{~dB}$ between the pre operative and post spinal PTA values. Statistical analysis included the one way ANOVA, two way ANOVA and Chi-square tests. RESULTS: The overall incidence of significant hearing loss in the study was $7.7 \%$. The percentage of patients developing significant hearing loss in groups $\mathrm{Y}, \mathrm{M} \&$ E were $6.6 \%, 13.3 \%$ and 3.3\% respectively. Only one patient in group $\mathrm{M}(3.3 \%)$ complained of mild post dural puncture headache (PDPH). The incidence of significant hearing loss in patients below 60 years was more compared with patients $>60$ years. CONCLUSION: Minor change in hearing threshold may occur after spinal anaesthesia and younger patients are more prone to it. KEY WORDS: Spinal Anaesthesia, Auditory functions, Pure-tone audiometry

INTRODUCTION: Spinal anaesthesia has few clear advantages over general anaesthesia as it is less costly, confers patient satisfaction and is more useful in patients with difficult airway and respiratory diseases, favorable for diabetic patients on account of little risk of unrecognized hypoglycemia and for faster return of gut functions postoperatively. Spinal anaesthesia produce complications such as pain on injection, backache, urinary retention to serious problems like hypotension, post dural headache (PDPH), neurological complications cranial nerve palsies and even cardiac arrest ${ }^{1}$.

Research in the last decade has added another one to the list of complications i.e impaired auditory function after spinal anaesthesia. Several studies have reported hearing loss after spinal anaesthesia suggesting that minor hearing defects frequently occur ${ }^{2-3}$. Hearing loss has also been reported in other clinical situations, involving opening of the duramater resulting 
in leakage of CSF like lumbar puncture ${ }^{4}$, myelography, vp shunts ${ }^{5}$, acoustic neuroma surgeries and neurosurgeries ${ }^{5}$.

On the basis of the hypothesis that patient age may affect hearing, we conducted an age comparative study to find out whether hearing loss differs between patients of different age groups receiving spinal anaesthesia.

MATERIAL AND METHODS: This prospective study was conducted on 90 patients of either gender with ASA I and II scheduled for elective surgery under spinal anaesthesia. Patients were divided into three groups on the basis of age. Group Y included 30 patients aged 30 years and below, group $\mathrm{M}$ included 30 patients aged 31 to 60 years and group E included 30 patients aged 61 years and above. A clinical oto-laryngological examination was done and pure tone audiometry in both ears was conducted under standardized conductions in a sound proof room by an experienced audiologists on the day prior to surgery (control value) and on the $2^{\text {nd }}$ postspinal postoperative day. A regularly calibrated audiometer (MA52 diagnostic Audiometer: MAICO) was used to test low frequencies, which was defined as $125 \mathrm{~Hz}, 250$ and $500 \mathrm{~Hz}$; speech frequencies defined as 500,1000, 2000 Hz and high frequencies defined as 2000, 4000,6000 $8000 \mathrm{~Hz}$. Hearing loss was considered significant if the difference between pre-operative and post spinal PTA values was $>15 \mathrm{~dB}$ statistical tests. Patients with conduction defects in external or middle ear, hearing impairment, acute otitis media, upper respiratory tract infection within one week of the surgery, Meniers disease, unwilling or uncooperative patients, patients on ototoxic medication (eg. aminoglycosides, salicylates, loop diuretics) were excluded from the study.

All patients were given Diazepam $.2 \mathrm{mg} / \mathrm{kg}$ body weight per oral on the day prior to surgery and Tab Diazepam $0.1 \mathrm{mg} . \mathrm{kg}$ orally in the morning on the day of surgery. Preloading was done with $10 \mathrm{ml} / \mathrm{kg}$ of ringer's lactate solution and intravenous fluid (crystalloid/colloid) was continued at 4-6 ml/kg/hour during entire surgical procedure and for the first 24 hours postoperatively to maintain SBP $>100 \mathrm{mmHg}$. If systolic blood pressure did not respond to fluid therapy, ephedrine was given as $6 \mathrm{mg}$ intravenously in incremental doses to bring the SBP to optimum level. Spinal anaesthesia was given in the lateral position using $2.8 \mathrm{ml}$ of $0.5 \%$ hyperbaric bupivacaine at the L2-3/L3-4 intervertebral space using 25 gauge Quincke needle. Intraoperative monitoring included heart rate, ECG and arterial saturation (SPO2) continuously during the surgery and for one hour postoperatively. Non invasive blood pressure was checked every five minutes for the first half an hour after spinal and every 15 minutes, there after till the end of surgery. Postoperatively NIBP was recorded hourly for the first four hours and thereafter 4 hourly for the first 24 hours.

Patients were visited twice daily upto 72 hours post operatively and were specifically questioned about any subjective symptoms regarding hearing loss, fullness in ears, tinnitus and nausea. Patients were also asked about post dural puncture headache and its severity was noted as: mild (slight restriction of patients physical activity), moderate (patients have to stay on bed part of the day) and severe (patients are bed ridden the entire day and make no attempts to raise their head or stand) ${ }^{7}$. Patients were also clinically examined for any dysfunction of the $3^{\text {rd }}$, $4^{\text {th }}, 6^{\text {th }}, 7^{\text {th }} \& 8^{\text {th }}$ cranial nerves.

Statistical analysis of demographic data was made using one way ANOVA test. Comparison of variations in hearing thresholds was done by two way ANOVA test, while comparison of cases found to have hearing loss $>15 \mathrm{~dB}$ by chi-square test. A p value of $<0.05$ was considered as statistically significant. 
RESULTS: The mean age of patients in group $Y$ was $25.8 \pm 3.64$ years, while in group $M$ it was $45.37 \pm 7.1$ year and in group $E$ the mean age was $67.43 \pm 5.9$ years. The gender distribution in all three groups was statistically comparable $(\mathrm{P}=0.180)$. All patients in group E belonged to ASA class II while in group Y and M only $10 \%$ and $23.3 \%$ of the patients belong to ASA class II. Most of the patients in study achieved a highest sensory block level of T10 and the difference in the highest level of sensory block achieved was statistically comparable among the three groups $(\mathrm{P}=0.731) \cdot($ Table 1$)$

All patients in the study remained stable haemodynamically. The lowest mean SBP values were statistically comparable among the study groups $(\mathrm{p}=0.13)$. The number of patients requiring vasopressor to maintain SBP $>100 \mathrm{~mm}$ Hg was 11,11 \& 7 in groups $\mathrm{Y}, \mathrm{M} \& \mathrm{E}$ respectively and this was statistically not different for the three study groups $(\mathrm{P}=0.443)$.

The overall incidence of significant hearing loss after spinal anaesthesia in the study was $7.7 \%$. In group Y 2 patients (6.6\%) developed significant hearing loss at $1000 \mathrm{~Hz}$. In groups M4 patients (13.3\%) had significant hearing loss (Table 2). One developed hearing loss at $125 \mathrm{~Hz}$ while the other 3 patients had hearing loss at $6000 \mathrm{~Hz}$ and $8000 \mathrm{~Hz}$. In group E only one patient (3.3\%) developed significant hearing loss at $250 \mathrm{~Hz}$.

In the higher frequencies tested by PTA there was no change between the preoperative and post operative values. In the left ear there was no significant change in PTA values at any of the low or high frequencies. In group $\mathrm{E}$ there was minor increase in the mean hearing threshold in the low and speech frequencies. While there was change in the high frequencies in the right ear, slight increase in mean hearing threshold was seen at all frequencies in the left ear.

On intergroup comparison of group $\mathrm{Y}$ and $\mathrm{M}$, the mean difference in hearing threshold was significant at $125 \mathrm{~Hz}(\mathrm{p}=0.002)$ and $250 \mathrm{~Hz}(\mathrm{p}=0.002)$ in the right ear. In the left ear mean difference in hearing threshold was significant at $1000 \mathrm{~Hz}(\mathrm{p}=0.001)$ and $2000 \mathrm{~Hz}(\mathrm{p}=0.002)$. In the right ear more hearing loss was seen in group Y at $125 \& 250 \mathrm{~Hz}$, while in the left ear it was more at 1000 and $2000 \mathrm{~Hz}$. On comparing group Y \& E no significant difference between the mean herring threshold was seen at any of the frequencies. On comparing the mean hearing threshold in group $\mathrm{M}$ and $\mathrm{E}$, we found statistically significant increase in mean hearing threshold at $250 \mathrm{~Hz}(\mathrm{p}=0.016)$ in the right ear and at $500 \mathrm{~Hz}(\mathrm{p}=0.043), 1000 \mathrm{~Hz}(\mathrm{p}=0.043)$, and $4000 \mathrm{~Hz}(\mathrm{p}=0.025)$ in the left ear.

Only one patient (3.35\%) in group M developed mild PDPH as compared to none of the patients in groups $\mathrm{Y}$ and $\mathrm{E}$. None of the patients in any groups had post spinal complications like subjective hearing loss, fullness in ears, tinnitus, dizziness, nausea or cranial nerve deficit in the post operative period. (Table 3).

DISCUSSION: Spinal anaesthesia is one of the most widely used techniques of regional anaesthesia ${ }^{1}$. The group allocation was according to age of the patients. Male and female distribution was statistically comparable in all the three groups. Group Y and group M had more patients belonging to ASAI while for group E all the patients (100\%) belonged to ASAII and this was probably on account of the age factor and comorbidites related to it.

The mean difference in the level of spinal block was not statistically significant between the three groups (Table3). Intraoperatively as well as post operatively the mean systolic and diastolic blood pressure was lower in group $\mathrm{Y}$ compared with group $\mathrm{M}$ and group $\mathrm{E}$ since elderly patients tend to have higher blood pressure values. Lowest recorded blood pressures were comparable among the three groups (Table 5 \& 6). 
PURE-TONE AUDIOMETRY: In our study, pure tone audiometry was done on two occasions, one preoperatively which was considered as base line value, and then on $2^{\text {nd }}$ post spinal day. PTA was conducted at low frequencies $(125,250,500 \mathrm{~Hz})$, speech frequencies $(500,1000$ and $2000 \mathrm{~Hz}$ ) and high frequencies $(2000,4000,6000$ and $8000 \mathrm{~Hz})$. In the present study we considered significant hearing loss as difference of $>150 \mathrm{~B}$ at any frequency between preoperative and postoperative PTA values. On comparing the number of patients who had an increase in hearing threshold of $>15 \mathrm{~dB}$ between pre-operative and post-operative values, we found that there were 2 patients $(6.6 \%)$ in group Y, 4 patients $(13.3 \%)$ in group M while only 1 patient (3.3\%) in group E had significant hearing loss.

On intergroup comparison group $\mathrm{Y}$ and group $\mathrm{M}$ were compared with each other, it was seen that the mean increase in hearing threshold at $125 \mathrm{~Hz}(\mathrm{p}=0.002)$ and $250 \mathrm{~Hz}(\mathrm{p}=0.002)$ was significantly more in the right ear while in the left ear the difference in hearing threshold was significantly more at $1000 \mathrm{~Hz}(\mathrm{p}=0.001)$ and $2000 \mathrm{~Hz}(\mathrm{p}=0.02)$ in group Y. When the difference in mean hearing threshold in group $\mathrm{M}$ was compared with group $\mathrm{E}$, we found statistically significant increase in mean hearing threshold at $250 \mathrm{~Hz}(\mathrm{P}=0.016)$ in the right ear and 500 , 1000 and $4000 \mathrm{~Hz}(\mathrm{P}=0.043,0.043$ and 0.025 ) respectively for the left ear (Table 5).

Gultekins and Ozcan $2002^{6}$ compared the incidence of hearing loss after spinal anaesthesia in young and elderly using PTA. They observed that there was significant hearing loss among the younger age group patients as compared to elderly in the low frequency range (52\% vs $16 \%)(\mathrm{P}=0.014)$.

In our study when we looked at the incidence of significant hearing loss in patients below 60 years of age, we found 6 out 60 patients below 60 years (2 patients in group Y and 4 patients in group M) had significant hearing loss i.e there was $10 \%$ incidence of hearing loss in patients below 60 years as compared with $3.3 \%$ in group E (age $>60$ years). We found that the overall incidence of hearing loss in patients below 60 years was lesser in our study $(10 \%)$ compared with the study by Gultiken et al (16\% in younger group). It could possibly be because of the fact that we defined significant hearing loss as difference between preoperative and post spinal PTA values was $\geq 15 \mathrm{~dB}$ whereas they had considered difference of $>10 \mathrm{~dB}$ as significant hearing loss. It has been explained that the direct connection between CSF and the perilymph via the cochlear aqueduct is the causative factor in hearing loss caused by spinal anaesthesia.

Gulay et al (2004) conducted 7 study to assess hearing loss in young adult patients aged 20-40 years after spinal anaesthesia and found no significant hearing loss in any of his patients. He commented that CSF leakage via the dural puncture hole may not be the only factor involved in hearing loss and changes in plasma osmolarity may influence hearing levels by causing changes in motility of the sensory cells (hair cell) of the organ of corti When we considered all the 90 patients in our study who developed hearing loss following spinal anaesthesia irrespective of age, total 7 patients out of 90 (7.7\%) patients had hearing loss in the low frequency following spinal anaesthesia .

Fog et $\mathrm{al}^{8}$ observed a decrease in hearing level $>10 \mathrm{~dB}$ at low frequency in 4 out of 14 patients (29\%) with the use of 26 gauge spinal needle. Again their incidence is much higher than the overall incidence in our study (7.7\%). The possible explanation for lesser incidence of hearing loss in our study could be that we defined significant hearing loss as difference of $15 \mathrm{~dB}$ or more between preoperative and postoperative PTA values.

Wang 3 demonstrated $42 \%$ hearing loss following spinal anaesthesia in patients undergoing TURP ${ }^{9}$. Sundberg et al observed very high incidence of low frequency hearing loss in patients undergoing TURP under spinal anaesthesia. 
It is well known that TURP itself produces profound alteration in fluid and electrolyte balance. The solution passes into the blood stream and causes changes in the osmolarity between blood and CSF. However in our study patients undergoing surgery were well distributed for various surgical procedures ie orthopaedics, obstetrics and gynaecology, general surgery and urology. This could be one of the factors for lesser incidence of hearing loss in our study (7.7\%) compared with Sundberg.

Patients were evaluated for any post spinal complications for a period of 72 hours postoperatively. None of the patients complained of subjective hearing loss, fullness in ear, tinnitus nausea or dizziness post operatively. There was no dysfunction of $3^{\text {rd }} 4^{\text {th }}, 6^{\text {th }}, 8^{\text {th }}$ cranial nerve observed post operatively in any patient.

Occurrence of hearing disorders after spinal anaesthesia has frequently been reported to be associated with post-spinal headache syndrome ${ }^{10}$. Several authors have suggested an association between post dural puncture headache and hearing loss ${ }^{3}$. PDPH is generally attributed to decrease intracranial pressure caused by CSF leak through the dural puncture a phenomenon similar to that attributed for hearing loss following spinal anaesthesia ${ }^{2}$.

In our study we found PDPH incidence was low (3.3\%) and there were no patients in group $\mathrm{Y}$ and group $\mathrm{E}$ who suffered from PDPH. In the middle age group one patient experienced mild PDPH which required only slight restriction of physical activity and this particular patient did not have hearing loss at any frequency hence we did not find any correlation between PDPH and hearing loss.

Sundberg (1992) ${ }^{9}$ also did not find any correlation between hearing loss and post spinal headache using either 22 gauge ((Quinqeor 22 gauge (whitcare).

Unexpected complication during postoperative period is puzzling experience for the anesthetist. Hearing loss is not an uncommon complication following spinal anaesthesia and patient's age may be an etiological factor. However it is usually transient and subtle but awareness regarding this is important in anaesthesia practice for medico legal implications and in specific set of patients such as pilots. Better understanding of the mysterious condition is crucial to improve safety profile.

\section{REFERENCES:}

1. Brown LD: Spinal, epidural and caudal anaesthesia. In; Miller RD, Anaesthesia $6^{\text {th }}$ ed Vol II 2005;43:1653-60.

2. Vandan L.D, Dripps R.D. Long term follow up of patients who received 10098 spinal anaesthetics JAMA 1956; 161:586-5913.

3. Wang LP, Fog J, Boe M. Transient hearing loss following spinal anaesthesia. Anaesthesia 1987; 42: 1258-63.

4. S.K. Malhotra, BA Iyer, A.K Gupta, M. Raghunathan, D. Nakra.Spinal analgesia and auditory functions: a comparison of two sizes of Quinoke needles. Minerve Anaesthesiol 2007; 73: 395-9

5. Walsted A. Effects of CSF loss on hearing Acta Otolaryngol; Suppl 2000; 543:95-98.

6. Gultekin S, Ozcan S. Does hearing loss after spinal anaesthesia differ between young and elderly patients? Anaesth Analg 2002; 94(5): 1318-20.

7. Corbey M.P, Berg P, Quqynor H. Classification and severity of PDPH comparison of 26G and 22G Quincke needle for spinal anaesthesia in day care surgery in patients under 45 years. Anaesthesia 1993;48:776-81. 
8. Gulay OK, Demet Tok, Koray Erbuyun. Hearing loss does not occur in young patients undergoing spinal anaesthesia. Reg Anesth Pain Med 2004; 29: 430-433.

9. Fog J, Wang LP, Sundberg A, Mucchiano C. Hearing loss after spinal anaesthesia is related to needle size Anaesth Analg 1990; 70: 517-22

10. Planning B, Lehnhardt E, Mehler D, Transient low frequency hearing loss following spinal anaesthesia (in German) Anaesthetist 1984; 33: 593-5.

11. Sundberg A, Wang LP Fog.J. Influence on hearing of 22G Qunckie needle Anesth 1992; 47: 981-3.

12. Wang LP. Sudden bilateral hearing loss after spinal anaesthesia: a case report. Acta Aaesthesiol Scand 1986;30: 412-3.

Table 1Distribution of patient's characteristic among various study groups.

\begin{tabular}{|l|l|l|l|}
\hline & \multicolumn{2}{|c|}{ Groups } & E \\
\hline $\begin{array}{l}\text { Age (in years) } \\
\text { Mean } \pm \text { SD }\end{array}$ & $25.80 \pm 3.64$ & $45.37 \pm 7.11$ & $67.43 \pm 5.96$ \\
\hline $\begin{array}{l}\text { Gender (M:F) } \\
\text { ASA status (1:2) }\end{array}$ & $27: 3$ & $23: 7$ & $24: 6$ \\
\hline $\begin{array}{l}\text { Highest level of } \\
\text { sensory block } \\
\text { (T10:T 9: T8) }\end{array}$ & $26: 4: 0$ & $25: 4: 1$ & $0: 30$ \\
\hline $\begin{array}{l}\text { Requirement } \\
\text { vasopressure } \\
\text { (Yes: No) }\end{array}$ & $11: 19$ & $11: 19$ & $26: 4: 0$ \\
\hline
\end{tabular}

Table 2 Distribution according to patients with significant hearing loss in each group

\begin{tabular}{|l|l|l|l|}
\hline Frequency HZ & Group Y (n\%) & Group M (n\%) & Group E (n\%) \\
\hline 125 & $0(0)$ & $1 .(3.3 \%)$ & $1(3.3 \%)$ \\
\hline 250 & $0(0)$ & $0(0)$ & $0(0)$ \\
\hline 500 & $0(0)$ & $0(0)$ & $0(0)$ \\
\hline 1000 & $2(6.65)$ & $0(0)$ & $0(0)$ \\
\hline 2000 & $0(0)$ & $0(0)$ & $0(0)$ \\
\hline 4000 & $0(0)$ & $0(0)$ & $0(0)$ \\
\hline 6000 & $0(0)$ & $2(6.65)$ & $0(0)$ \\
\hline 8000 & $0(0)$ & $1(3.3 \%)$ & $0(0)$ \\
\hline Total n\% & $2(6.6 \%)$ & $4(13.3)$ & $1(3.3)$ \\
\hline
\end{tabular}


Table 3 Distribution according to severity to post dural puncture headache (PDPH)

\begin{tabular}{|l|l|l|l|l|}
\hline & \multicolumn{4}{|c|}{ Group } \\
\hline & $\begin{array}{l}\mathrm{Y} \\
\mathrm{n}(\%)\end{array}$ & $\begin{array}{l}\mathrm{M} \\
(\mathrm{n} \%)\end{array}$ & $\begin{array}{l}\mathrm{E} \\
(\mathrm{n} \%)\end{array}$ & P-value \\
\hline Mild & $0(0)$ & $1(3.3)$ & $0(0)$ & .403 \\
\hline Moderate & $0(0)$ & $0(0)$ & $0(0)$ & \\
\hline Severe & $0(0)$ & $0(0)$ & $0(0)$ & \\
\hline
\end{tabular}

Table 4 Intra Group Comparison of Group Y and M

\begin{tabular}{|l|l|l|l|l|l|l|}
\hline & \multicolumn{3}{|l|}{} & \multicolumn{2}{l|}{ Group M } & \multicolumn{2}{c|}{} \\
\cline { 2 - 6 } & Right ear & Left ear & Right ear & \multicolumn{2}{l|}{ Left ear } & \multicolumn{2}{l}{} \\
\hline $\begin{array}{l}\text { Frequency } \\
(\mathrm{Hz})\end{array}$ & $\begin{array}{l}\text { Difference } \\
\text { Mean } \pm \text { SD }\end{array}$ & $\begin{array}{l}\text { Difference } \\
\text { Mean } \pm \text { SD }\end{array}$ & $\begin{array}{l}\text { Difference } \\
\text { Mean } \pm \text { SD }\end{array}$ & $\begin{array}{l}\text { Difference } \\
\text { Mean } \pm \text { D }\end{array}$ & $\begin{array}{l}\text { P value } \\
\text { Right ear }\end{array}$ & $\begin{array}{l}\text { P value } \\
\text { Left ear }\end{array}$ \\
\hline 125 & $-3.16 \pm 4.44$ & $-1 \pm 7.70$ & $-0.16 \pm 2.45$ & $0 \pm 6.29$ & .002 & .584 \\
\hline 250 & $-3.5 \pm 3.74$ & $-2.5 \pm 10.31$ & $0.16 \pm 4.82$ & $0.66 \pm 7.03$ & .002 & .170 \\
\hline 500 & $-3.33 \pm 5.14$ & $-1 \pm 11.09$ & $-1 \pm 5.78$ & $1.83 \pm 9.32$ & .104 & .289 \\
\hline 1000 & $-3.66 \pm 6.93$ & $-5.33 \pm 6.68$ & $-2.83+4.29$ & $0.33 \pm 5.71$ & .578 & .001 \\
\hline 2000 & $-0.83 \pm 7.20$ & $-4.83 \pm 5.64$ & $-1 \pm 5.78$ & $-0.16 \pm 5.64$ & .922 & .002 \\
\hline 4000 & $-2.66 \pm 7.39$ & $-2 \pm 5.81$ & $-1.66 \pm 5.14$ & $1.33 \pm 7.97$ & .546 & .070 \\
\hline 6000 & $-1.33 \pm 6.14$ & $-4.5 \pm 7.46$ & $-1.83 \pm 5.79$ & $-3.66 \pm 10.66$ & .747 & .727 \\
\hline 8000 & $-0.33 \pm 4.472$ & $-1.33 \pm 8.19$ & $-1.5 \pm 7.78$ & $-2.16 \pm 8.47$ & .486 & .700 \\
\hline
\end{tabular}

Intra Group Comparison of Group Y and E

\begin{tabular}{|l|l|l|l|l|l|l|}
\hline & \multicolumn{2}{|l|}{ Group Y } & Group E & \multicolumn{2}{c|}{} \\
\cline { 2 - 6 } & Right ear & Left ear & Right ear & \multicolumn{2}{l|}{ Left ear } & \multicolumn{2}{c|}{} \\
\hline $\begin{array}{l}\text { Frequency } \\
(\mathrm{Hz})\end{array}$ & $\begin{array}{l}\text { Difference } \\
\text { Mean } \pm \text { SD }\end{array}$ & $\begin{array}{l}\text { Difference } \\
\text { Mean } \pm \text { SD }\end{array}$ & $\begin{array}{l}\text { Difference } \\
\text { Mean } \pm \text { SD }\end{array}$ & $\begin{array}{l}\text { Difference } \\
\text { Mean } \pm \text { D }\end{array}$ & $\begin{array}{l}\text { P value } \\
\text { Right ear }\end{array}$ & $\begin{array}{l}\text { P value } \\
\text { Left ear }\end{array}$ \\
\hline 125 & $-3.16 \pm 4.44$ & $-1 \pm 7.70$ & $-1.16 \pm 3.86$ & $-1.16 \pm 9.06$ & .068 & .939 \\
\hline 250 & $-3.5 \pm 3.74$ & $-2.5 \pm 10.31$ & $-3 \pm 5.017$ & $-1.16 \pm 2.84$ & .664 & .498 \\
\hline 500 & $-3.33 \pm 5.14$ & $-1 \pm 11.09$ & $-2.66 \pm 5.37$ & $-2.16 \pm 5.03$ & .625 & .602 \\
\hline 1000 & $-3.66 \pm 6.93$ & $-5.33 \pm 6.68$ & $-2.16+4.67$ & $-2.5 \pm 4.86$ & .330 & .066 \\
\hline 2000 & $-0.83 \pm 7.20$ & $-4.83 \pm 5.64$ & $-0.66 \pm 2.53$ & $-4.33 \pm 11.19$ & .905 & .828 \\
\hline 4000 & $-2.66 \pm 7.39$ & $-2 \pm 5.81$ & $-0.16 \pm 5.94$ & $-2.66 \pm 5.20$ & .154 & .642 \\
\hline 6000 & $-1.33 \pm 6.14$ & $-4.5 \pm 7.46$ & $-2.33 \pm 5.20$ & $-1.83 \pm 6.22$ & .499 & .138 \\
\hline 8000 & $-0.33 \pm 4.472$ & $-1.33 \pm 8.19$ & $-0.33 \pm 4.34$ & $-1.83 \pm 5.94$ & .571 & .788 \\
\hline
\end{tabular}




\section{Intra Group Comparison of Group $M$ and $E$}

\begin{tabular}{|c|c|c|c|c|c|c|}
\hline & \multicolumn{2}{|l|}{ Group M } & \multicolumn{2}{|l|}{ Group E } & & \\
\hline & Right ear & Left ear & Right ear & Left ear & & \\
\hline $\begin{array}{l}\text { Frequency } \\
(\mathrm{Hz})\end{array}$ & $\begin{array}{l}\text { Difference } \\
\text { Mean } \pm \text { SD }\end{array}$ & $\begin{array}{l}\text { Difference } \\
\text { Mean } \pm \text { SD }\end{array}$ & $\begin{array}{l}\text { Difference } \\
\text { Mean } \pm \text { SD }\end{array}$ & $\begin{array}{l}\text { Difference } \\
\text { Mean } \pm \text { D }\end{array}$ & $\begin{array}{l}\text { P value } \\
\text { Right ear }\end{array}$ & $\begin{array}{l}\text { P value } \\
\text { Left ear }\end{array}$ \\
\hline 125 & $-0.16 \pm 2.45$ & $0 \pm 6.29$ & $-1.16 \pm 3.86$ & $-1.16 \pm 9.06$ & .237 & .565 \\
\hline 250 & $0.16 \pm 4.82$ & $0.66 \pm 7.03$ & $-3 \pm 5.017$ & $-1.16 \pm 2.84$ & .016 & .191 \\
\hline 500 & $-1 \pm 5.78$ & $1.83 \pm 9.32$ & $-2.66 \pm 5.37$ & $-2.16 \pm 5.03$ & .252 & .043 \\
\hline 1000 & $-2.83+4.29$ & $0.33 \pm 5.71$ & $-2.16+4.67$ & $-2.5 \pm 4.86$ & .567 & .043 \\
\hline 2000 & $-1 \pm 5.78$ & $-0.16 \pm 5.64$ & $-0.66 \pm 2.53$ & $-4.33 \pm 11.19$ & .774 & .074 \\
\hline 4000 & $-1.66 \pm 5.14$ & $1.33 \pm 7.97$ & $-0.16 \pm 5.94$ & $-2.66 \pm 5.20$ & .300 & .025 \\
\hline 6000 & $-1.83 \pm 5.79$ & $-3.66 \pm 10.66$ & $-2.33 \pm 5.20$ & $-1.83 \pm 6.22$ & .727 & .419 \\
\hline 8000 & $-1.5 \pm 7.78$ & $-2.16 \pm 8.47$ & $-0.33 \pm 4.34$ & $-1.83 \pm 5.94$ & .265 & .861 \\
\hline
\end{tabular}

